\title{
A Discrete Population of Mononuclear Phagocytes Detected by Monoclonal Antibody
}

\author{
PAUL A. LEBLANC, * HOWARD R. KATZ, AND STEPHEN W. RUSSELL \\ Departments of Pathology and Bacteriology/Immunology and the Cancer Research Center, University of \\ North Carolina, Chapel Hill, North Carolina 27514
}

\begin{abstract}
Rat monoclonal antibody raised against cultured mouse bone marrow was used to detect an antigenic determinant on a discrete population of mouse mononuclear phagocytes by indirect immunofluorescence. The antigen was expressed on adherent, late-cultured bone marrow macrophages and chronic inflammatory peritoneal macrophages elicited by the injection of thioglycolate broth. Binding of the antibody to resident peritoneal or alveolar macrophages, blood monocytes, or freshly explanted bone marrow cells was not detected. Less than $10 \%$ of acute inflammatory mononuclear phagocytes expressed the antigen. The antibody did not bind detectably to lymphocytes, granulocytes, erythrocytes, fibroblasts, or the cells of several murine tumor lines. Results suggesting binding to mast cells were equivocal. The antigen was species, but not strain, specific. It was concluded that maturation, at least, was required for expression of the antigen. Results suggested that additional influences were also involved.
\end{abstract}

The mononuclear phagocyte system is functionally heterogeneous (for reviews, see references 19 and 21). One approach to the investigation of such heterogeneity centers on the detection of antigens that mark discrete populations of mononuclear phagocytes. Reagents directed against such antigens would allow the enrichment or depletion of antigenically distinct populations, thereby fostering definitive analysis of the functional role(s) that these cells may have. Description by Kaplan and Mohanakumar (8) of an antiserum that detected only macrophages that had been activated to kill tumor cells has lent credibility to this approach.

The essential element in investigations of this kind is an indicator reagent that is truly specific for the subject antigen. Conventionally raised antisera are notoriously difficult to render specific. However, the advent of the hybridoma technique (10) has helped immeasurably in overcoming the problem of specificity. The methodology allows production of so-called monoclonal antibody, with specificity for a single antigenic determinant. Such highly specific probes are potentially of great value in explaining prior observations of functional heterogeneity among mononuclear phagocyte populations.

Using the hybridoma technique, we have produced a monoclonal antibody that marks a discrete population of mononuclear phagocytes. The following remarks characterized this antibody and the population of cells to which it binds.

\section{MATERIALS AND METHODS}

Animals. Mice of strains BALB/c, C57BL/6, and $\mathrm{C} 3 \mathrm{H} / \mathrm{HeN}$ were obtained from ARS/Sprague-Dawley (Madison, Wis.). Strain A/He and outbred Swiss mice were purchased from Charles River Breeding Laboratories (Wilmington, Mass.). All mice were used at 7 to 8 weeks of age. Eight-week-old Lewis rats were obtained from Microbiological Associates (Walkersville, Md.). Female New Zealand white rabbits were purchased from Dutchland Laboratory Animals, Inc. (Denver, Pa.). Golden hamsters were the gift of F. W. Henderson, Department of Pediatrics, of this institution.

Cells. Cells for antibody binding assay were harvested from cultures in mid-log-phase growth. BALB/ 3T3 (1), L929 (American Type Culture Collection CCL1), P815 mastocytoma (5), and MSC rhabdomyosarcoma (12) cell lines were carried antibiotic-free in $N$-2-hydroxyethylpiperazine- $N^{\prime}$-2-ethanesulfonic acid (HEPES)-buffered (15 mM) modified Eagle minimal essential medium (MEM) containing glutamine (2 $\mathrm{mM}$ ) and fetal bovine serum (FBS; $10 \%$ final concentration). The cultures were incubated in a humidified atmosphere of $5 \% \mathrm{CO}_{2}$ in air at $37^{\circ} \mathrm{C}$. The mouse myeloma line Sp2/O-Ag14 (16) was a gift from Ralph Reisfeld (Research Institute of Scripps Clinic, La Jolla, Calif.). Sp2/O cells were propagated in Dulbecco MEM supplemented with FBS (20\% final concentration) and 8-azaguanine $(25 \mu \mathrm{g} / \mathrm{ml})$ under a moist atmosphere containing $10 \% \mathrm{CO}_{2}$ at $37^{\circ} \mathrm{C}$. No evidence of mycoplasma contamination was found by culture or fluorescent dye analysis of cells for extranuclear deoxyribonucleic acid (4).

Resident peritoneal macrophages were harvested from unstimulated animals by peritoneal lavage, as described by Ruco and Meltzer (15). Peritoneal exu- 
dates were elicited with either purified, phenol-extracted lipopolysaccharide (13) from Escherichia coli (0111:B4), a gift of David Morrison (Department of Microbiology, School of Medicine, Emory University, Atlanta, Ga.), or Brewer modified thioglycolate broth (Difco Laboratories, Detroit, Mich.). Mice injected with lipopolysaccharide were given $50 \mathrm{ng}$ intraperitoneally. Exudates were harvested by peritoneal lavage at times indicated in the text. Thioglycolate broth was injected intraperitoneally, either 1 or 4 days before cells were harvested, by peritoneal lavage. The dose was $3 \mathrm{ml}$ for mice, $5 \mathrm{ml}$ for rats and hamsters, and 15 $\mathrm{ml}$ for rabbits.

To obtain resident alveolar macrophages, a catheter was inserted into the trachea. The lungs were then flushed with $10 \mathrm{ml}$ of MEM containing heparin (2 U/ ml) (14).

Spleen, thymus, and mesenteric lymph nodes were removed aseptically and separately teased in ice-cold medium to prepare single-cell suspensions.

Liquid bone marrow culture. The protocol of Buhles and Shifrine (3) was followed. Briefly, mice were treated with cyclophosphamide (Sigma Chemical Co., St. Louis, Mo.) to increase the number of mononuclear phagocyte colony-forming cells in their bone marrows. An initial dose of $250 \mathrm{mg} / \mathrm{kg}$ was given subcutaneously, after which repeated doses of $50 \mathrm{mg}$ / $\mathrm{kg}$ were administered every other day, beginning at day 3, until day 17. Bone marrow was harvested on day 19 by flushing the femora and tibiae. Nucleated cells $\left(5 \times 10^{6}\right)$ were seeded into $10 \mathrm{ml}$ of bone marrow growth medium (MEM plus 10\% FBS, 10\% L-cell conditioned medium, and $5 \%$ horse serum) contained in a 100 -mm diameter, tissue culture-grade petri dish. After 3 to 4 days, plates were washed to remove loosely adherent granulocyte colonies. Mononuclear phagocyte colonies were more tightly adherent and, consequently, remained attached to the plastic during washing. Mononuclear phagocytes were removed by using a rubber policeman. At least $95 \%$ of the recovered cells were of the mononuclear phagocyte series, as determined by esterase staining (6).

Production of monoclonal antibodies. A Lewis rat was injected intramuscularly with $10^{7}$ bone marrow culture-derived mouse mononuclear phagocytes suspended in complete Freund's adjuvant. Three intraperitoneal injections $\left(10^{7}\right.$ cells each, in saline) followed at weekly intervals, after which the rat was rested for 8 weeks. A final exposure $\left(2 \times 10^{6}\right.$ mononuclear phagocytes intravenously and $10^{7}$ intraperitoneally) was then given. The rat was killed 3 days later, and its spleen was excised aseptically.

Mouse myeloma cells (Sp2/0-Ag14) were fused with the rat's spleen cells, using $30 \%$ polyethylene glycol 1500 (BDH Chemicals Limited, distributed by GallardSchlesinger Chemical Manufacturing Corp., Carle Place, N.Y.) dissolved in Dulbecco MEM by the method of Kennett et al. (9). The next day, cells were distributed into flat-bottomed wells of microtest plates (no. 3596, Costar, Cambridge, Mass.) in Dulbecco MEM supplemented with HAT $\left(1 \times 10^{-4} \mathrm{M}\right.$ hypoxanthine, $4 \times 10^{-7} \mathrm{M}$ aminopterin, and $3 \times 10^{-6} \mathrm{M}$ thymidine). Every other day, half of the medium was removed from each well and replaced with fresh HAT. containing medium. Approximately 14 days after fusion, macroscopic evidence of cell growth appeared in some of the wells (ultimately 394 of 2,000). An indirect binding assay was used to detect antibody production by individual outgrowths (11). Supernatants were tested directly from wells, i.e., without cloning. Antibody was detected by incubating supernatants with indicator cells (either bone marrow-derived mononuclear phagocytes or BALB-3T3 cells), then with rabbit anti-rat immunoglobulin and, finally, with staphylococcal protein A (Pharmacia Fine Chemicals, Inc., Piscataway, N.J.) labeled with ${ }^{125}$ I. Eighty-seven of the 394 wells contained antibody that bound to mononuclear phagocytes but not to 3T3 cells. The hybrid populations from these 87 wells were expanded and stored frozen in liquid nitrogen. They were then individually thawed and cloned by limiting dilution.

Typing antisera. Class- and subclass-specific antisera raised against rat immunoglobulins were purchased from Miles Research Products (Elkhart, Ind.). Antisera to rat immunoglobulin G (IgG), IgM, and IgG2b were produced in rabbits. Antisera against IgG2a and IgG2c were produced in goats. Antiserum against rat IgG1 was raised in sheep.

Indirect fluorescence microscopy. All staining and washing procedures were conducted on ice. Cells in suspension (except adherent bone marrow cells which were attached to cover slips) were exposed to either clone or Sp2/0-Ag14 myeloma cell supernatants for $30 \mathrm{~min}$. After two washes in Hanks balanced salt solution, fluoresceinated $F\left(a^{\prime}\right)_{2}$ rabbit anti-rat immunoglobulin (2) was used as the developing reagent. This reagent had been absorbed with mouse spleen and resident peritoneal cells to remove all vestiges of anti-mouse immunoglobulin and macrophage activities. After three additional washes in Hanks balanced salt solution, cells were examined with a phase/fluorescence microscope. Cells incubated with control $\mathrm{Sp} 2 / 0$ supernatant followed by fluoresceinated $\mathrm{F}\left(\mathrm{ab}^{\prime}\right)_{2}$ rabbit anti-rat immunoglobulin were absolutely negative for membrane fluorescence in every instance.

\section{RESULTS}

Characterization of antibody-producing clone 54-2. Preliminary examination by indirect immunofluorescence indicated that antibody produced by the 54th hybrid outgrowth stained mononuclear phagocyte populations differentially. These cells were therefore selected for further study. The cells were cloned by limiting dilution to ensure that the observed reactivity was the result of a monoclonal product. The clone with the highest reactivity (designated $\mathrm{Cl}$ 54-2) was selected and expanded for use.

The stability of $\mathrm{Cl}$ 54-2 with regard to antibody production was assessed by subcloning. In this experiment, 5 of 10 subclones continued to produce antibody, indicating a degree of instability. In view of this finding, large numbers of producer cells were stored frozen in liquid nitro- 
gen. Thawed cells have continued to produce antibody of the same specificity.

The class and subclass of rat antibody produced by $\mathrm{Cl}$ 54-2 was determined by Ouchterlony analysis, using specific antisera. The antibody was identified as IgG2a by this approach.

Examination of bone marrow cells. Bone marrow cells from cyclophosphamide-treated mice were examined by indirect immunofluorescence, either directly or after liquid culture. There was no detectable staining of the freshly explanted cells by $\mathrm{Cl}$ 54-2 antibody. In culture, expression of the relevant antigen developed gradually on adherent cells, reaching a maximum of $73 \%$ positive by 4 days (Fig. 1A). The cells that stained were mature-looking mononuclear phagocytes as judged by phase-contrast microscopy. The pattern of staining was that of discrete membrane fluorescence, ranging in intensity from brilliant to dim. Nonadherent cells, which included immature mononuclear phagocytes and granulocytes, failed to bind the antibody detectably. Similar results were obtained with bone marrow cells from mice that had not been treated with cyclophosphamide (data not shown).

To confirm that immature, nonadherent mononuclear phagocytes would begin to express the relevant antigen as they matured, nonadherent cells from 4-day cultures were transferred into fresh culture vessels. With time, a portion of these cells adhered and began to express

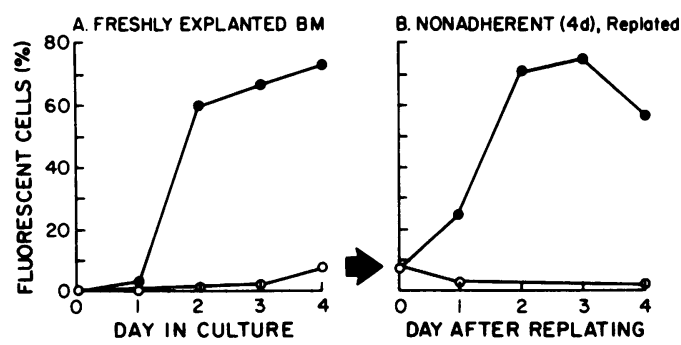

FIG. 1. Indirect immunofluorescence examination of liquid cultured bone marrow cells with $\mathrm{Cl}$ 54-2 antibody. Symbols: $\bigcirc$, nonadherent cells; $\bigcirc$, adherent cells. (A) Bone marrow was flushed from the tibiae and femora of cyclophosphamide-treated mice. Cells in bone marrow growth medium were plated into petri dishes containing 12-mm-diameter glass cover slips. At each time point, plates were agitated and nonadherent cells were collected in the supernatant medium. Cover slips bearing the adherent population were rinsed. Both adherent and nonadherent cells were examined by indirect immunofluorescence. (B) On day 4 of culture, as shown by the arrow, nonadherent cells were recovered, washed, and replated as in (A). Adherent and nonadherent cells were examined at 24-h intervals thereafter, as described above. antigen (Fig. 1B). The maximal level of staining reached was that which was seen in the original culture. Again, granulocytes and other cells that remained either loosely adherent or in suspension failed to stain detectably. These results suggested that expression of the antigen detected by $\mathrm{Cl}$ 54-2 antibody was associated with maturation in culture. An alternative explanation was that the antigen was acquired passively from the culture medium. It was therefore important to determine whether mature mononuclear phagocytes that had never been in culture bound the antibody.

Examination of resident peritoneal and alveolar mononuclear phagocytes. Mature mononuclear phagocytes were obtained by either peritoneal or pulmonary lavage. The composition of each of these cell populations, as determined by differential analysis, is given in Table 1. Despite the high percentage of mononuclear phagocytes in these suspensions, very few cells stained $(1.6 \%$ for the peritoneal cells and $0.1 \%$ for those from the lung). The few cells that did exhibit membrane fluorescence were large and granular.

Examination of acute and chronic inflammatory populations. The inflammatory response alters mononuclear phagocytes morphologically and functionally. Both acute and chronic inflammatory populations of mononuclear phagocytes were examined, therefore, to determine whether they would bind the monoclonal antibody produced by $\mathrm{Cl} 54-2$. Table 2 shows the composition and staining properties of the acute (24-h) and chronic (4-day) peritoneal cell populations. Of the acute inflammatory cells, either 2 or $8 \%$ stained, depending upon the eliciting agent. In contrast to the low percentage of staining detected in acute exudates, $86 \%$ of the chronic inflammatory cells bound the monoclonal antibody. It is important to note that

TABLE 1. Examination of resident peritoneal and alveolar mononuclear phagocytes

\begin{tabular}{lcc}
\hline & \multicolumn{2}{c}{ Origin of Cells } \\
\cline { 2 - 3 } \multicolumn{1}{c}{ Examination by: } & $\begin{array}{c}\text { Perito- } \\
\text { neal cav- } \\
\text { ity (\%) }\end{array}$ & $\begin{array}{c}\text { Lung } \\
(\%)\end{array}$ \\
\hline $\begin{array}{l}\text { Indirect immunofluorescence, cells } \\
\text { binding Cl 54-2 antibody }\end{array}$ & 1.6 & 0.1 \\
Differential analysis $^{a}$ & & \\
$\quad$ Mononuclear phagocytes & 69 & 59 \\
$\quad \begin{array}{l}\text { Lymphocytes } \\
\text { Granulocytes }\end{array}$ & 26 & 13 \\
Mast cells & 3 & 28 \\
\end{tabular}

${ }^{a}$ As determined by differential analysis of Wrightstained cytocentrifuge preparations.

${ }^{b}$ Both neutrophils and eosinophils. 
TABLE 2. Examination of acute and chronic inflammatory mononuclear phagocytes

\begin{tabular}{lccc}
\hline & \multicolumn{3}{c}{$\%$ Cells } \\
\cline { 2 - 3 } \multicolumn{1}{c}{ Examination by: } & \multicolumn{2}{c}{ Acute $^{a}$} & \\
\cline { 2 - 3 } & LPS & Thio & \\
\cline { 2 - 3 } Chronic $^{b}$ \\
\hline Indirect immunofluorescence, & 2 & 8 & 86 \\
$\quad$ cells binding Cl 54-2 antibody & & & \\
Differential analysis & & & \\
Mononuclear phagocytes & 51 & 33 & 89 \\
Lymphocytes & 19 & 8 & 11 \\
Neutrophils & 23 & 56 & 0 \\
Eosinophils & 7 & 3 & 0 \\
Mast cells & 0 & 0 & 0 \\
\hline
\end{tabular}

${ }^{a}$ Induced by the intraperitoneal injection of either $50 \mathrm{ng}$ of lipopolysaccharide (LPS) or $3 \mathrm{ml}$ of Brewer modified thioglycolate broth (Thio) $24 \mathrm{~h}$ before cells were harvested by peritoneal lavage.

${ }^{b}$ Induced by the intraperitoneal injection of $3 \mathrm{ml}$ of Brewer modified thioglycolate broth 4 days before cells were harvested by peritoneal lavage.

c As determined by differential analysis of Wright-stained cytocentrifuge preparations.

none of these cells had been exposed to the tissue culture reagents that were used to culture mouse bone marrow. Furthermore, an $\mathrm{F}\left(\mathrm{ab}^{\prime}\right)_{2}$ fragment prepared by pepsin digestion from the monoclonal antibody continued to show similar levels of staining when tested against thioglycolate-elicited macrophages (data not shown).

Examination of monocytes. The mononuclear phagocytes in inflammatory lesions are derived predominantly from blood monocytes. Because a few mononuclear phagocytes in acute peritoneal exudates stained, it was necessary to determine whether none, or a portion, of monocytes bound the antibody produced by $\mathrm{Cl} 54-2$. Buffy-coat cells were isolated from mice with cyclophosphamide-induced monocytosis (40\% monocytes) and examined in suspension by indirect immunofluorescence, using $\mathrm{Cl}$ 54-2 antibody. None stained detectably.

Examination of cell types other than mononuclear phagocytes. Table 3 gives the results of examining cell suspensions from a variety of sources, each rich in cell types other than mononuclear phagocytes. Very little staining was obtained with these populations. Thus, it was possible to conclude that neither granulocytes, thymocytes, peripheralized lymphocytes, erythrocytes, nor cultured fibroblasts bound the antibody in detectable amounts. As before, the infrequent cell that stained was large and granular.

The morphological appearance of the large, granular cell suggested that it could be a mast cell. To test this possibility, a drop of new methylene blue dye was allowed to diffuse under the cover slip while the cell of interest, previously located by indirect immunofluorescence, was ob- served. In three of four attempts, the large granules stained metachromatically, thereby supporting the hypothesis that these cells were mast cells.

Thioglycolate-elicited macrophages of mouse strains other than BALB/c. To determine whether the antigenic determinant detected by $\mathrm{Cl}$ 54-2 antibody was strain specific, mice other than BALB/c $\left(H-2^{d}\right)$ were examined. Mice of different histocompatibility types were chosen, including $\mathrm{C} 57 \mathrm{BL} / 6\left(H-2^{b}\right), \mathrm{A} / \mathrm{He}\left(H \cdot 2^{a}\right)$, and $\mathrm{C} 3 \mathrm{H} / \mathrm{HeN}\left(H-2^{k}\right)$. Outbred mice (Swiss) were also examined. As for BALB/c mice, thioglycolate broth was injected 4 days before harvest of peritoneal exudates. Staining levels were comparable in all mice tested (Table 4).

Peritoneal macrophages of species other than mice. The peritoneal macrophages of rats

TABLE 3. Examination by indirect immunofluorescence of cell populations low in mononuclear phagocytes

\begin{tabular}{lc}
\hline \multicolumn{1}{c}{ Origin of cells } & $\begin{array}{c}\text { Cells bind- } \\
\text { ing Cl 54-2 } \\
\text { antibody } \\
\text { (no. posi- } \\
\text { tive/no. } \\
\text { counted) }\end{array}$ \\
\hline Freshly explanted & \\
Spleen & $1 / 528$ \\
Lymph node & $3 / 766$ \\
Thymus & $0 / 623$ \\
6-h peritoneal exudate ${ }^{a}$ & $0 / 500$ \\
Culture & \\
BALB/3T3 (fibroblast) & $0 / 500$ \\
L929 & $0 / 500$ \\
P815 (mastocytoma) & $0 / 500$ \\
MSC (rhabdomyosarcoma) & $0 / 500$ \\
Sp2/0-Ag14 (myeloma) & $0 / 500$ \\
\hline
\end{tabular}

${ }^{a}$ Induced by intraperitoneal injection of $50 \mathrm{ng}$ of lipopolysaccharide (E. coli 0111:B4) 6 h before cells were harvested by peritoneal lavage. Differential analysis of Wright-stained cytocentrifuge preparations: $37 \%$ mononuclear phagocytes, $19 \%$ lymphocytes, $40 \%$ polymorphonuclear leukocytes, $4 \%$ mast cells.

TABLE 4. Examination of thioglycolate-elicited peritoneal macrophages from several mouse strains $^{a}$

\begin{tabular}{lcc}
\hline Strain & $H-2$ type & $\begin{array}{c}\text { Cells binding } \\
\text { Cl 54-2 anti- } \\
\text { body }^{b}(\%)\end{array}$ \\
\hline BALB/c & $d$ & 77 \\
$\mathrm{C} 3 \mathrm{H} / \mathrm{HeN}$ & $k$ & 72 \\
$\mathrm{C} 57 \mathrm{BL} / 6$ & $b$ & 84 \\
$\mathrm{~A} / \mathrm{He}$ & $a$ & 82 \\
Swiss & & 80 \\
\hline
\end{tabular}

${ }^{a}$ Induced by the intraperitoneal injection of $3 \mathrm{ml}$ of Brewer modified thioglycolate broth 4 days before cells were harvested by peritoneal lavage.

${ }^{b}$ As determined by indirect immunofluorescence. 
(Lewis), golden hamsters, and rabbits (New Zealand white) were examined, with and without thioglycolate elicitation. None of the cells bound the monoclonal antibody, as detected by indirect immunofluorescence.

\section{DISCUSSION}

This is the first report of a monoclonal antibody that detects an antigen that is expressed by a discrete population of mouse mononuclear phagocytes. It was detected, using a rat monoclonal antibody, on the surfaces of late-cultured bone marrow mononuclear phagocytes and on chronic (4-day) inflammatory macrophages elicited by the intraperitoneal injection of thioglycolate broth. The antigen was not detectable on resident peritoneal macrophages, alveolar macrophages, or blood monocytes. Less than $10 \%$ of acute inflammatory mononuclear phagocytes bound the antibody detectably.

In contrast to our findings, the antigens described in previous studies of mononuclear phagocytes were shared more broadly over the spectrum of mononuclear phagocyte differentiation. For example, Mac-1 (17) was found on bone marrow cells and on spleen and blood monocytes, as well as on mature splenic and thioglycolate-elicited peritoneal exudate macrophages. In addition, macrophage antigens previously detected by monoclonal antibodies have been shared with either granulocytes (17) or lymphocytes (20). MSMA, a mouse macrophage-specific antigen identified with conventionally prepared antiserum (18), was found on splenic and peritoneal macrophages. A variety of other cell types did not express the antigen; however, neutrophils were not examined. MSMA was also detectable on the peritoneal macrophages of rats and hamsters. By comparison, the antigen detected in our studies was not found, at the level of sensitivity of indirect fluorescence microscopy, on the mononuclear phagocytes of three species other than mice, nor was it found on granulocytes or lymphocytes. Whether $\mathrm{Cl}$ 54-2 antibody bound to mast cells will have to be reexamined by using immunoelectron microscopy before a definite statement can be made, in view of the facts that (i) populations which contained significant numbers of mast cells failed to show detectable binding (see 6-h peritoneal exudate, Table 3), (ii) P815 mastocytoma cells failed to bind detectable levels of the antibody, (iii) not all of the large, granular, fluorescence-positive cells stained metachromatically, and (iv) although strongly suggestive, metachromatic staining of granules is not conclusive evidence that a cell is a mast cell.

One nonmonoclonal antiserum has been re- ported to bind only to macrophages activated for tumor cell killing $(7,8)$. Whether this reagent was detecting one or a number of antigens on activated cells cannot be determined from the information that was given. Regardless of whether an antigen or antigens were detected, it is clear that this antiserum was defining a distinct, functional population of mononuclear phagocytes.

The functional significance of the antigen detected by $\mathrm{Cl} 54-2$ is not yet known. Whatever it is discovered to be, we find especially attractive the possibility that the antigen may be a marker for macrophages in chronic inflammatory sites. Resident macrophages are present in the peritoneal cavity at the time inflammation is initiated. Blood monocytes migrate into the peritoneal cavity in response to inflammatory stimuli. Either one or both of these populations, therefore, represented the progenitors of the cells that eventually expressed the antigen in chronic inflammatory exudates. Neither resident macrophages nor the blood monocytes bound $\mathrm{Cl}$ 54-2 antibody detectably. Similarly, exudates collected from acute inflammatory reactions did not contain a high percentage of cells that were positive for the antigen. Yet, in the presence of a chronic irritant, thioglycolate broth for 4 days, most of the macrophages bound $\mathrm{Cl}$ 54-2 antibody. Whether chronic inflammation provided a positive signal to drive the cells to express the antigen, or a closed site in which the cells were freed from putative normal, negative controls, is presently under study.

It is clear, however, that whichever of these mechanisms is operative, it alone is insufficient to cause expression of the antigen. Maturation was additionally required. This conclusion can be drawn from the experiments that are illustrated in Fig. 1, wherein nonadherent, immature mononuclear phagocytes failed to express the antigen in spite of its induction in the adherent, mature population.

A final comment is needed regarding the extent to which artifact might be responsible for our findings. The fact that the antigen recognized by Cl 54-2 antibody was not found on a variety of cultured cell types and was strongly expressed on thioglycolate-elicited macrophages that had never been in culture made it unlikely that the antigen was acquired passively from the tissue culture system. Conversely, the antigen was not directly related to thioglycolate broth, because mononuclear phagocytes in bone marrow culture bound the antibody. Finally, it is also unlikely that antibody was binding to cells via interaction with $\mathrm{Fc}$ receptors. The $\mathrm{F}\left(\mathrm{ab}^{\prime}\right)_{2}$ fragment of $\mathrm{Cl}$ 54-2 antibody continued to show 
similar levels of staining with thioglycolate-elicited mononuclear phagocytes as the whole antibody.

In conclusion, we have described an antigen that is expressed by a discrete population of mouse mononuclear phagocytes. The finding of one such marker increases the likelihood that others may be identifiable by a similar approach. Should such prove to be the case, it is our hope that they will be of use in gaining a better understanding of mononuclear phagocyte differentiation and the biology of inflammation in host defense.

\section{ACKNOWLEDGMENTS}

We thank M. Pacilio, A. Rountree, and P. Wurster for their technical assistance and B. Brown for preparation of the manuscript.

This work was supported by Public Health Service research grant CA 23686 and training grant CA 09057, both from the National Cancer Institute. P.A.L. is the recipient of Public Health Service national research service award CA 06088 and S.W.R. is the recipient of Public Health Service research career development award CA 00497, both from the same Institute.

\section{LTERATURE CITED}

1. Aaronson, S. A., and G. J. Todaro. 1968. Development of 3T3-like lines from BALB/c mouse embryo cultures: transformation susceptibility to SV40. J. Cell. Physiol. 72:141-148.

2. Babcock, G. F., L. L. Lanier, M. A. Lynes, and G. Haughton. 1978. A simple method for the preparation of antisera specific for murine immunoglobulin heavy chains. J. Immunol. Methods 23:1-6.

3. Buhles, W. C., Jr., and M. Shifrine. 1977. Effects of cyclophosphamide on macrophage numbers, functions and progenitor cells. J. Reticuloendothel. Soc. 21:285297.

4. Chen, T. R. 1977. In situ detection of mycoplasma contamination in cell cultures by fluorescent Hoechst 33258 stain. Exp. Cell Res. 104:255-262.

5. Dunn, T. B., and M. Potter. 1957. A transplantable mastcell neoplasm in the mouse. J. Natl. Cancer Inst. 18: 587-601.

6. Goud, T. J. L. M., C. Schotte, and R. van Furth. 1975. Identification and characterization of the monoblast in mononuclear phagocyte colonies grown in vitro. J. Exp. Med. 142:1180-1199.

7. Kaplan, A. M., H. D. Bear, L. Kirk, C. Cummins, and
T. Mohanakumar. 1978. Relationship of expression of a cell-surface antigen on activated murine macrophages to tumor cell cytotoxicity. J. Immunol. 120:2080-2085.

8. Kaplan, A. M., and T. Mohanakumar. 1977. Expression of a new cell surface antigen on activated murine macrophages. J. Exp. Med. 146:1461-1466.

9. Kennett, R. H., K. A. Denis, A. S. Tung, and N. R. Klinman. 1978. Hybrid plasmacytoma production: fusions with adult spleen cells, monoclonal spleen fragments, neonatal spleen cells and human spleen cells. Curr. Top. Microbiol. Immunol. 81: 77-91.

10. Kohler, G., and C. Milstein. 1975. Continuous cultures of fused cells secreting antibody of predefined specificity. Nature (London) 256:495-497.

11. LeBlanc, P. A., S. M. Taffet, F. A. Fried, and F. P. Avis. 1979. Staphylococcal protein A assay for detection of antibody directed at renal cancer cells. J. Urology 121:724-727.

12. Massicot, J. G., W. A. Woods, and M. A. Chirigos. 1971. Cell line derived from a murine sarcoma virus (Moloney pseudotype)-induced tumor: cultural, antigenic, and virological properties. Appl. Microbiol. 22: 1119-1122.

13. Morrison, D. C., and L. Leive. 1975. Fractions of lipopolysaccharide from Escherichia coli O111:B4 prepared by two extraction procedures. J. Biol. Chem. 250:29112919.

14. Myrvik, Q. N., E. S. Leake, and B. Fariss. 1961. Studies on pulmonary alveolar macrophages from the normal rabbit: a technique to produce them in a high state of purity. J. Immunol. 86:128-132.

15. Ruco, L. P., and M. S. Meltzer. 1978. Macrophage activation for tumor cytotoxicity: increased lymphokine responsiveness of peritoneal macrophages during acute inflammation. J. Immunol. 120:1054-1062.

16. Shulman, M., C. D. Wilde, and G. Kohler. 1978. A better cell line for making hybridomas secreting specific antibodies. Nature (London) 276:269-270.

17. Springer, T., G. Galfre, D. S. Secher, and C. Milstein. 1979. Mac-1: a macrophage differentiation antigen identified by monoclonal antibody. Eur. J. Immunol. 9:301306.

18. Stinnett, J. D., A. M. Kaplan, and P. S. Morahan. 1976. Identification of a macrophage-specific cell surface antigen. J. Immunol. 116:273-278.

19. Stuart, A. E. 1977. The heterogeneity of macrophages: a review, p. 1-14. In K. James, B. McBride, and A. Stuart (ed.), The macrophage and cancer. University of Edinburgh, Medical School, Edinburgh, Scotland.

20. Unkeless, J. C. 1979. Characterization of a monoclonal antibody directed against mouse macrophage and lymphocyte Fc receptors. J. Exp. Med. 150:580-596.

21. Walker, W. S. 1976. Functional heterogeneity of macrophages, p. 91-110. In D. S. Nelson (ed.), Immunobiology of the macrophage. Academic Press, Inc., New York. 